\title{
Material Cycles and Chemicals: Dynamic Material Flow Analysis of Contaminants in Paper Recycling
}

Pivnenko, Kostyantyn; Laner, David; Astrup, Thomas Fruergaard

\section{Published in:}

Environmental Science and Technology

Link to article, DOI:

10.1021/acs.est.6b01791

Publication date:

2016

Document Version

Publisher's PDF, also known as Version of record

Link back to DTU Orbit

Citation (APA):

Pivnenko, K., Laner, D., \& Astrup, T. F. (2016). Material Cycles and Chemicals: Dynamic Material Flow Analysis of Contaminants in Paper Recycling. Environmental Science and Technology, 50(22), 12302-12311.

https://doi.org/10.1021/acs.est.6b01791

\section{General rights}

Copyright and moral rights for the publications made accessible in the public portal are retained by the authors and/or other copyright owners and it is a condition of accessing publications that users recognise and abide by the legal requirements associated with these rights.

- Users may download and print one copy of any publication from the public portal for the purpose of private study or research.

- You may not further distribute the material or use it for any profit-making activity or commercial gain

- You may freely distribute the URL identifying the publication in the public portal 


\title{
Material Cycles and Chemicals: Dynamic Material Flow Analysis of Contaminants in Paper Recycling
}

\author{
Kostyantyn Pivnenko, ${ }^{* \dagger}$ David Laner, ${ }^{\ddagger}$ and Thomas F. Astrup ${ }^{\dagger}$ \\ ${ }^{\dagger}$ Department of Environmental Engineering, Technical University of Denmark, DK-2800 Kgs. Lyngby, Denmark \\ ${ }^{\ddagger}$ Institute for Water Quality, Resources and Waste Management, Vienna University of Technology, Karlsplatz 13, 1040 Wien, Austria
}

Supporting Information

ABSTRACT: This study provides a systematic approach for assessment of contaminants in materials for recycling. Paper recycling is used as an illustrative example. Three selected chemicals, bisphenol A (BPA), diethylhexyl phthalate (DEHP) and mineral oil hydrocarbons (MOHs), are evaluated within the paper cycle. The approach combines static material flow analysis (MFA) with dynamic material and substance flow modeling. The results indicate that phasing out of chemicals is the most effective measure for reducing chemical contamination. However, this scenario was also associated with a considerable lag phase (between approximately one and three decades) before the presence of chemicals in paper products could be considered insignificant. While improved decontami-

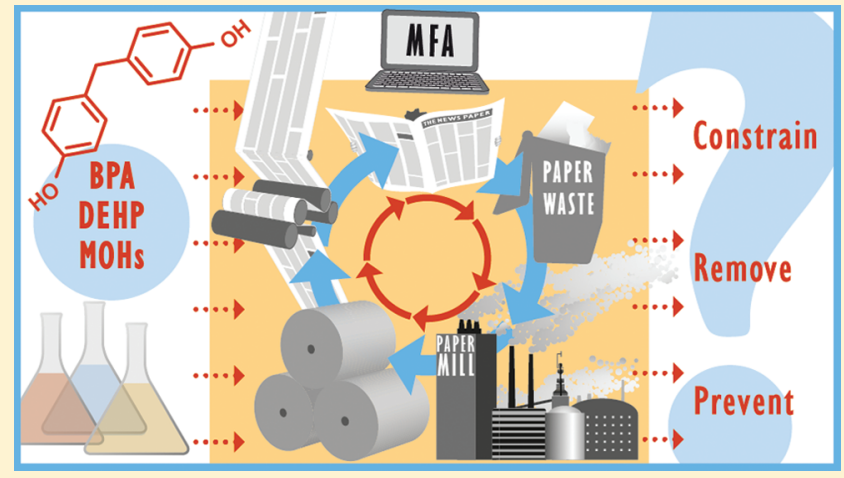
nation may appear to be an effective way of minimizing chemicals in products, this may also result in lower production yields. Optimized waste material source-segregation and collection was the least effective strategy for reducing chemical contamination, if the overall recycling rates should be maintained at the current level (approximately $70 \%$ for Europe). The study provides a consistent approach for evaluating contaminant levels in material cycles. The results clearly indicate that mass-based recycling targets are not sufficient to ensure high quality material recycling.

\section{INTRODUCTION}

Recycling of materials and products is a backbone of sustainable development, a term that was coined almost three decades ago. ${ }^{1}$ The main benefits typically associated with material recycling are a reduced dependency on natural resources and nonrenewable energy sources, as well as a reduction in our environmental footprint. ${ }^{2}$ This has been recognized by the European Union (EU), resulting in adoption of a resolution on "resource efficiency: moving towards a circular economy" in 2015 $(2014 / 2208$ (INI)). Similar trends in increasing focus on recycling can also be observed for the US. ${ }^{3}$ While in most cases, material recycling appears to be beneficial from a general "sustainability" perspective, the case might be oversimplified.

To live up to the ever-increasing demands for functionality, appearance, durability, etc., the chemical and material complexity of industrial and consumer products have increased. Metal alloys substitute pure metals, chemical additives increase the flexibility and durability of plastics, flame retardants reduce the fire risks of electronics and textiles, pigments and inks improve the appearance of products, etc. When products containing a multitude of constituents are recovered for recycling and reprocessing, their complex chemistry comes along with them. On this basis, a cycle consisting of both materials and chemicals is created, parts of which are being constantly added and removed from the cycle. ${ }^{4}$
Paper is a good example of a commodity that is consumed in large quantities, with about $200 \mathrm{~kg}$ per capita being annually consumed in the US and the EU. ${ }^{5}$ Literature has indicated the presence of a wide range of chemicals in paper and paper products; up to 10000 chemicals may potentially be present in the final products, with paper conversion (printing, gluing, etc.) being the main source. ${ }^{6}$ The chemicals that are used in paper are most commonly employed in the form of solvents, inks, and dyes, polymeric formulations, etc. Additionally, chemicals may be unintentionally added through impurities and as chemical byproducts, or introduced through contamination during use. ${ }^{7}$ Paper is also the material with one of the highest recycling rates worldwide, with more than 230 million tonnes collected for recycling in 2012. ${ }^{8}$ This value results in a global average recycling rate of $58 \%$, which is even higher for newspapers (67\%) and paper packaging (81\%) recycled in the US and Europe, respectively. ${ }^{3,5}$ On average, paper is recycled 3.5 times before being removed from the paper cycle, ${ }^{5}$ although the actual number of cycles for paper fiber is expected to be lower. ${ }^{9,10}$ Consequently, contamination of newly manufactured paper products with chemicals present in recycled paper and board can

Received: April 11, 2016

Revised: August 15, 2016

Accepted: August 30, 2016 
be expected, unless these chemicals are removed in the reprocessing. Once removed these chemicals may be released into the environment, potentially making paper mills an important source of environmental pollution. ${ }^{11-14}$ Paper products that are based on recycled paper have been shown to have a higher chemical load compared with virgin-fiber based products. ${ }^{15}$ Although the majority of chemicals present in paper products is benign, some chemicals are regarded as hazardous. ${ }^{6}$ The presence of chemicals has been linked to increased toxicity and risks associated with the use of recycled paper, particularly in food-contact applications (see, e.g., refs 16-18). Understanding the fate of a chemical once it is introduced into a paper product remains a key challenge when assessing the risks and potential limitations associated with paper recycling.

Material flow analysis (MFA) can be used to systematically quantify the flows and stocks of materials in arbitrarily complex systems, distinguishing flows at the goods level with the substances that are contained within these goods. ${ }^{19}$ Thereby, MFA may provide useful information regarding the patterns of resource use and losses of materials entering the environment. ${ }^{20}$ MFA is typically referred to as a substance flow analysis (SFA), when a specific substance is the focus of the investigation. Therefore, SFA can be used as tool for providing information about the flows of chemicals, their distribution and fate in a product cycle, thereby identifying problematic flows or emissions and creating a basis for designing mitigation strategies. ${ }^{21}$ Depending on whether an MFA is carried out for a certain time increment or whether it describes the stocks and flows of a material system over several time increments, it is static or dynamic. Static MFA is used to provide a snapshot of a system in time and can be done at different levels of aggregation to investigate use patterns and losses in the system. Dynamic MFA provides information about material usage over time and consequent changes in stocks and flows within a system. ${ }^{22} \mathrm{~A}$ combined use of both static and dynamic MFA can provide a more comprehensive understanding of material cycles and the importance of chemical substances in the recycled materials.

The overall aim of this study is to provide and evaluate a systematic modeling approach for assessment of chemicals in recyclable materials and potential strategies for mitigating contamination of the associated material cycles. Paper recycling in Europe is used as a case to illustrate the modeling approach, rather than provide specific predictions for European paper and chemical flows. Focus is placed on three potentially hazardous chemicals: bisphenol A (BPA), diethylhexyl phthalate (DEHP), and mineral oil hydrocarbons (MOHs). The following specific objectives are included: to (i) establish a reconciled paper cycle for Europe, based on a static MFA model; (ii) establish a dynamic SFA model for BPA, DEHP, and MOHs within the paper material cycle; (iii) compare and evaluate selected strategies for minimizing the presence of these chemicals in paper products through scenario analysis; and (iv) on this basis, provide recommendations for improved management of paper for recycling.

\section{MATERIALS AND METHODS}

Material and Substance Flow Modeling. The modeling approach used in this study was based on the method of MFA and consisted of static, as well as dynamic material and substance flow modeling. ${ }^{19}$ The approach builds on establishing a reconciled paper flow model, which is used to assess the flows of selected chemicals in various paper products along the product life-cycle, and finally to investigate chemical cycling in paper products based on scenario analysis. The overall procedure consisted of four steps and is illustrated in Figure 1.

In the first step, the paper flows in Europe were quantified for the year 2012, which was chosen according to data availability.
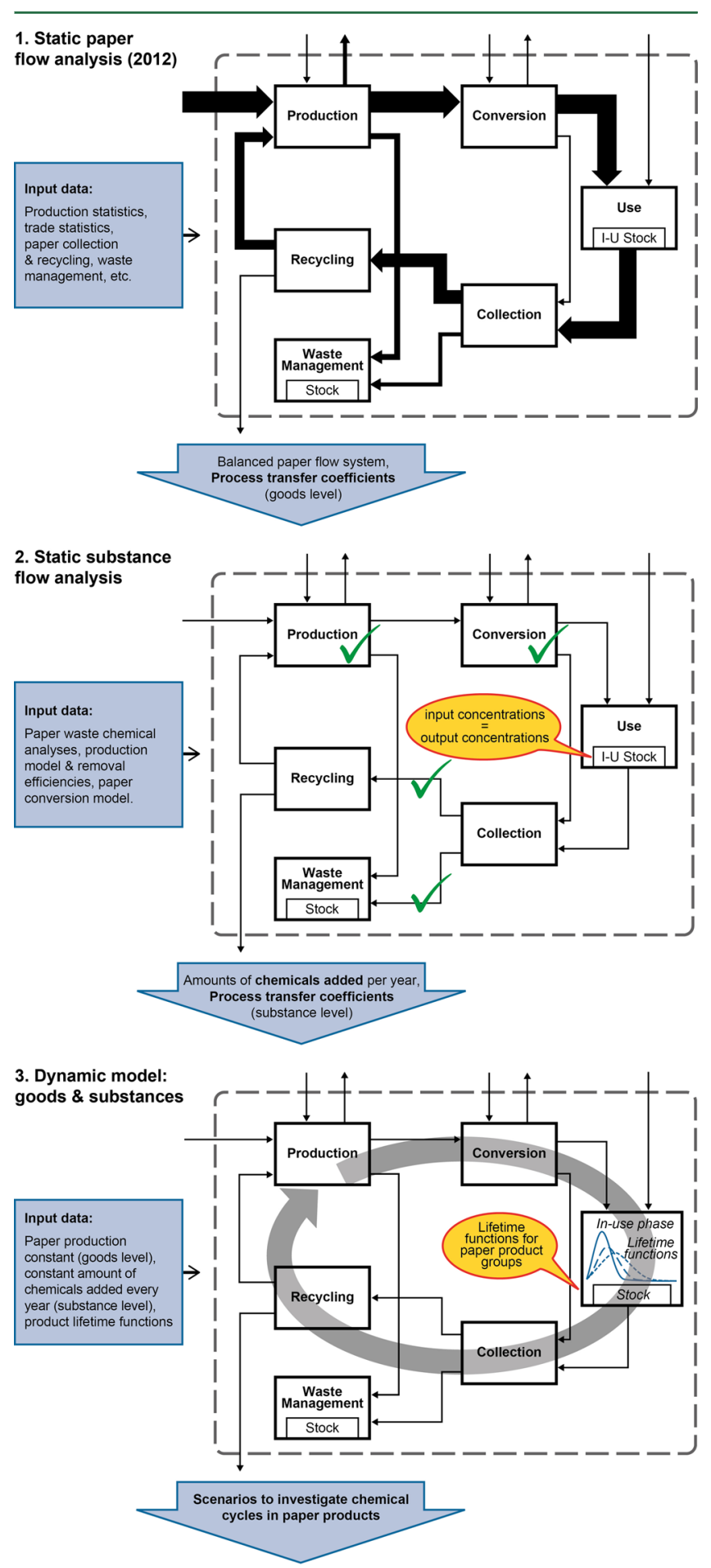

4. Scenario analysis

Figure 1. Approach of combining static and dynamic material flow modeling to investigate the chemical dynamics in paper products using scenario analysis. Flows across the system boundary represent the imports and exports of paper products and waste paper. The tick marks in step two indicate the elements for which information on chemical concentration and partitioning was used to estimate the annual steadystate addition of chemicals in step three. 
On the basis of the fully balanced paper flow system, transfer coefficient (TC) matrices were derived for each process. TCs defined the partitioning of input flows to the various output flows of a process. These TC matrices formed the basis for the second step focusing on modeling the flows of chemicals in paper products (Figure 1). In the third step, outputs from step one and two were used to establish a dynamic model of the paper cycle. Using this model setup as a basis, step four investigated a range of scenarios for mitigating the cycling of contaminants in paper products. Further details of the modeling are provided in the following.

Static Paper Flow Analysis. The paper flows were determined in a static MFA using the STAN software (www.stan2web.net). STAN is a widely used tool to perform MFA, offering the possibility for propagation of errors, as well as data reconciliation within the material flow model. ${ }^{23}$ Conflicting material flow data may occur due to overdetermination of the mass balance equation system. ${ }^{23}$ Such flows can be reconciled in STAN, based on characterization of the input data uncertainty, which is used to alter the mean flow values in order to comply with the mass balance constraints of the model. In the present study, the data were characterized as normally distributed variables, defined by the mean value and relative standard deviation (RSD). Three levels of uncertainty were assigned to the input data, according to the origin of the material flow data, hence following a simple classification approach. ${ }^{24}$ Data originating from statistical reports were assigned a RSD of 5\%. Data for discarded paper flows were assigned a RSD of $10 \%$ and transfer coefficients estimated based on process understanding were associated with larger RSDs (between 10 and 50\%), depending on the confidence in the available information (e.g., paper grade-specific fiber losses to solid residues during paper production were assigned a RSD of $30 \%)$. In this study, the main purpose of the uncertainty characterization is to assign "weights" to the various input data, which are then reconciled using the mass balance equations (the higher the uncertainty, the lower the weight). The reconciliation procedure is used to check data plausibility and reduce flow uncertainties. ${ }^{25}$ After a closed mass balance was achieved for the paper flow model, the transfer coefficient matrices for each process were derived. These matrices were used to define the production and use pattern of paper in the investigated system with respect to seven individual paper product categories: "carton board" (CB), "case materials" (CM), "household and sanitary" (H\&S), "newsprint" (NP), "other graphic paper" (OG), "other paper" (OP) and "wrappings and packaging" (WP). The transfer coefficient matrices formed the basis for balancing the substance flows within the paper products and for building the dynamic material flow model.

Static Substance Flow Analysis. The chemical flows associated with the paper products were determined by considering three substance layers within the material flow model in STAN. The flows of BPA, DEHP, and MOHs were calculated using the concentrations of these chemicals in paper fractions discarded from Danish households (Table S1), as well as the fate of these chemicals during paper production and conversion. Using this information and assuming identical substance concentrations for the paper product inputs to and outputs from the use phase (i.e., ignoring the time lag between input and output) in the substance flow modeling (Figure 1), the amount of chemicals introduced during the different paper lifecycle stages was calculated. For BPA, the share of BPA used in thermal paper (constituent of "other paper") was added during production, while BPA used in other paper product categories (e.g., for gluing) was added during conversion. On the other hand, for both DEHP and MOHs, the chemicals were added during conversion. Addition during use (e.g., potential oil contamination of tissue paper ${ }^{26}$ ) or any other steps in the paper cycle were also assumed to occur during conversion for simplification.

Dynamic Modeling of Material and Substance Flows. A dynamic model of the paper cycle was established using the TC matrices derived from the static material flow modeling at the goods (step one) and substance layers (step two), as well as the annual amount of chemicals added to the paper products as calculated in step two. The in-use stock of paper products was accounted for based on lifetime functions, which defined the period from when a specific paper product enters the use phase until it is discarded. Weibull functions were used to express the in-use product lifetimes and the product-specific parameters were obtained from Cote et al. ${ }^{27}$ who established a dynamic model of paper stocks and flows in Germany between 2010 and 2040. It is apparent from Supporting Information Table S2 that many of the paper products have expected residence times in the in-use stock of around one year (H\&S, NP, and WP). Half of the OG products are expected to be out of use after four years; for $\mathrm{CM}$ and $\mathrm{CB}$ this corresponds to around 3.5 years. The product group OP is a mixture of products with varying lifetimes. This resulted in a low minimum lifetime $\left(t_{0}\right)$ and a rather long average residence time ( $50 \%$ discarded after 13 years). The latter is due to the presence of paper products as books, archives, catalogs, construction paper (e.g., wallpaper), etc., which usually remain in use for an extended period. Nevertheless, the sensitivity of the model with respect to the lifetime functions assumed was assessed using alternative lifetimes where minimum lifetime was assumed to be zero (see section 8 of the Supporting Information)).

The dynamic model achieves a closed mass balance-at the level of goods (paper) as well as substances (chemicals). Therefore, paper and contained chemicals were either recycled (and therefore kept in the paper product cycle) or directed toward waste management for energy recovery, landfilling, composting, or other waste management options (e.g., anaerobic digestion). The paper flows were kept constant at the 2012 level and, once the dynamic model converged to a steady state, it resembled the current (2012) paper system in Europe. After a sufficiently high number of modeling years $(>35)$, both goods and chemicals reached a (quasi) steady state. This was subsequently used as a reference scenario (SC0) for comparison with alternative mitigation scenarios addressing the effects of specific measures for minimization of the chemical levels in the paper cycle (Table S3). The dynamic model calculations were performed in MS Excel using the iterative mode (maximum change between iterations below 0.001).

The assumption of a steady state in the dynamic modeling of the European paper product cycle is a simplification because historic paper and board consumption have been increasing continuously. ${ }^{28}$ However, consumption has slowed down in recent years, ${ }^{29}$ and the main purpose of the steady state model is to provide a basis for evaluating the effects of different mitigation measures on the flows of chemicals in paper products. ${ }^{30}$

Scenario Analysis. Three alternative management scenarios were investigated (SC1-SC3) and compared with the reference scenario (SC0), which represented the case in which no action to limit the presence of the selected chemicals was taken, that is, business as usual (BAU). Table S3 provides an overview of the four scenarios that are defined as follows: 
i) In the reference scenario (SC0), the paper flows are kept constant and chemical flows reach the steady state level (no mitigation measures).

(ii) Scenario one (SC1) aimed at minimizing the chemical content of paper products through optimizing the collection of paper for recycling. This would indicate the optimal distribution between paper fractions being recycled and diverted into alternative waste management options (e.g., incineration). The rates of paper recycling were maintained, at least at the current level. The optimization was formulated into a linear problem, which was solved using the solver in MS Excel.

iii) In scenario two (SC2), it was assumed that the removal efficiency of chemicals in paper reprocessing itself was improved. This could potentially be the result of, for example, conventional deinking processes covering larger shares of recycled paper or improvements in the efficiency of the deinking processes themselves (see, e.g., ref 31). The scenario assumed that current removal efficiencies would be doubled within one year. Increased removal efficiencies also result in reduced yields in paper production, as larger amounts of fibers and other paper constituents are discarded as sludge. The scenario assumed an increase of $20 \%$ in residues, which were discarded as sludge.

iv) Scenario three (SC3) evaluated the effects from potential developments in legislation or industry standards promoting the phase-out of BPA, DEHP, or MOHs in paper and paper products, for example, substitution of the three chemicals by available alternatives (see, e.g., refs 32-35). This scenario assumed a five-year linear decrease, until no more BPA, DEHP, or MOHs was intentionally added. Assuming a uniform distribution of a chemical in paper products, concentrations of BPA, DEHP, and MOHs were calculated and compared to analytical limits of detection (LOD), which were achieved by Pivnenko et al. ${ }^{36}$ In this case, LOD indicated a threshold below which the presence of a chemical in paper products could be considered insignificant.

Data Sources. Goods Level (Paper). To build the database of paper flows in Europe a consistent terminology was used, incorporating established frameworks for the paper recycling and waste management. ${ }^{10,37}$ Paper flows resulting from the use phase are referred to as "discarded paper", which subdivides into "paper for recycling"-if discarded paper is segregated and intended for recycling, and "residual paper"-if discarded paper is not intended for recycling and is commonly disposed of as part of mixed solid waste. Due to high paper recycling rates in Europe, most of the discarded paper is routed to recycling, while residual paper is largely limited to paper fractions not suitable for recycling (e.g., food packaging, tissue paper, wallpaper, and cigarette paper). Overall, the collected data were used to quantify the flows of the seven paper product categories throughout the entire material flow model (Table S4 and S5). Most of the data on paper production, consumption, conversion, and collection of paper for recycling in 2012 were obtained from the Confederation of European Paper Industries, CEPI. ${ }^{28}$ The member countries of CEPI represent $95 \%$ of the European pulp and paper industry in terms of production. ${ }^{28}$ Thermal paper was additionally considered in "other paper", with an estimated production of 168000 tonnes, ${ }^{38}$ as CEPI production data did not contain thermal paper. Detailed data for import and export of paper products (Table S5) were based on data provided in the United Nations Commodity Trade Statistics (UN Comtrade) Database for 2012. ${ }^{39}$ In addition to the direct imports, unreported imports of paper products as, for example, paper packaging, were also taken into account as nonapparent consumption and described in section 1 of the Supporting Information. Composition of the discarded paper was based on data from a detailed household waste characterization campaign in Denmark. ${ }^{36,40}$ The partitioning of discarded paper into four grades of recycled paper (A, mixed grades; $\mathrm{B}$, corrugated and Kraft; C, newspapers and magazines; D, high grades) was based on statistics data provided by $\mathrm{CEPI}^{28}$ and complemented by the European list of standard grades of paper and board for recycling (EN 643/2013) and an annual report on pulp and paper industry. ${ }^{41}$ Production efficiency and the resulting flows of residues to sludge and solid residues were based on literature data ranges for different paper grades (Table S6). ${ }^{42}$

Substance Level (Chemicals). On the basis of the recent review of potentially hazardous chemicals that can result in paper contamination, ${ }^{6}$ three different chemicals were included at the substance level as prominent examples: BPA, DEHP, and MOHs. BPA is primarily used as a developer in thermal paper production. ${ }^{43}$ Although being used in limited applications, the current high concentrations of BPA in thermal paper may result in potential contamination of paper products through recycling (see, e.g., refs 36 and 43-45). DEHP is a representative of phthalates, a group of chemicals raising concerns about their presence in paper products. ${ }^{6,46}$ Phthalates are primarily used as plasticizers in lacquers and dispersion glues preparations or printing ink formulations. $\mathrm{MOHs}$ are a group of chemicals that are identified as contaminants, potentially originating from recycled paper (e.g., refs 6,15, 26, and 47). The ink solvents that are used in printing processes are the main source of $\mathrm{MOH}$ in paper products, ${ }^{48}$ and concerns about recycled paper contamination and potential health risks related to the presence of MOHs have been expressed. ${ }^{17,48,49}$

For these chemicals, the concentrations in the individual paper product categories contained in discarded paper (Table S1) were based on detailed studies from Denmark. ${ }^{36,43}$ While the Danish data were not expected to be representative for all of Europe, the data provided a useful estimate of the potential presence of the selected chemicals in European paper flows. Concentrations of chemicals in imported products (including nonapparent consumption) were assumed to be the same as in paper products that are produced within the CEPI member countries.

Information about the removal efficiencies of chemicals during paper reprocessing was gathered from various sources, while chemicals added in the paper conversion step were distributed into different paper product categories in accordance with their presence in discarded paper (Table S1). Literature values on removal efficiencies vary widely, depending on technology, individual process specifications, level of contamination, etc. In the case of BPA, the average removal efficiencies during paper reprocessing are reported to be between $10 \%$ and $30 \% .{ }^{13}$ In the present study, BPA removal efficiency was defined related to the recycling paper grades: $95 \%$ of BPA in paper grade C (mainly "newsprint" and "other graphic paper") and 10\% of BPA in the other paper grades (A, B, and D). The values were based on estimates provided by the EU risk assessment report on $\mathrm{BPA},{ }^{38}$ in which the removal efficiency of BPA in deinked paper for recycling (predominantly applied in graphic paper production) was $95 \%$, in contrast to the $10 \%$ estimated for non-deinked paper. With respect to DEHP, $20 \%$ of the chemical entering 
production via recycling paper was assumed to be removed. ${ }^{50}$ Around $80 \%$ of $\mathrm{MOH}$ contained in paper for recycling could be removed in a two-stage flotation process, simultaneously losing approximately $40 \%$ of the paper fiber input. ${ }^{51}$ Other flotation experiments achieved $\mathrm{MOHs}$ removal efficiencies of around $50 \%$, with fiber losses being approximately $15 \%$ of the input. ${ }^{52}$ Therefore, the average MOHs removal efficiencies were assumed to be $40 \%$ within the paper production process in the model. No consistent data could be found regarding potential losses of chemicals through evaporation, migration, transformation, etc. (e.g., relevant for the waste collection phase). While such contributions are likely to be small and marginal compared to other flows, omissions may potentially lead to slight underestimation of chemical amounts in e.g., paper products.

\section{RESULTS AND DISCUSSION}

Static Paper Flow Analysis. A static paper flow model for the European market in 2012 was developed. The reconciled model for paper flows is shown in Figure S1. The resulting transfer coefficients for the processes of the paper cycle are available in Tables S8-S14. The total paper and board production in 2012 was $93 \pm 1.6$ Mtonnes. The paper production resulted in seven main paper product categories, with OG (32 \pm 1.1 Mtonnes $)$ and CM (25 \pm 0.97 Mtonnes $)$ having the highest production shares. As evident from Figure S1, $11 \pm 3.8$ million tonnes of paper and board were annually accumulated as a stock during the use phase, promoted by growth in paper consumption and resulting in outputs from the use phase (discarded paper) being outweighed by the inputs (paper products). Imports of paper products for use were $1.3 \pm 0.07$ Mtonnes and paper indirectly imported into Europe, mostly as packaging, accounted for $5.8 \pm 2.9$ Mtonnes. The majority of discarded paper was collected for recycling, while only $13 \pm 0.5$ Mtonnes ended up in the residual waste and "escaped" the recycling loop. Of the $53 \pm$ 2.0 Mtonnes of paper collected for recycling, $8.3 \pm 1.2$ Mtonnes were net exports (= exports - imports) included in the official calculations of the European paper recycling rates. ${ }^{53}$ The largest share of the residual paper was landfilled (63\%), while $32 \%$ were incinerated with or without energy recovery. Residual paper ending up as compost or diverted to other waste management options (e.g., anaerobic digestion) was minor (approximately $5 \%)$. Landfilled residual paper and production residues increased the landfill stocks by $11 \pm 0.53$ Mtonnes.

The largest amount of residues $(31 \pm 3.1$ Mtonnes $)$ was derived from pulp production (e.g., debarking and pulping residues) and is commonly utilized for on-site energy production. Similarly, the paper converting residues (5.1 \pm 0.22 Mtonnes) have limited contamination and are usually collected separately from the discarded paper. They are used directly in paper production as high-grade paper.

In light of the lack of a clear definition of material recycling, ${ }^{54}$ literature has provided different suggestions (e.g., refs 55-57). Applying the most common definition, that is, the ratio of the total paper collected for recycling relative to the total paper consumed, to the reconciled paper cycle (Figure S1) resulted in a recycling rate of $70 \pm 4 \%$, which is close to the $72 \%$ reported by CEPI. ${ }^{28}$ However, this figure may be misleading as a share of paper for recycling is exported and reprocessed in other geographical areas (e.g., China), ${ }^{29}$ or is lost in the paper reprocessing as residues and sludge composed primarily of short paper fibers and nonfibrous paper components. ${ }^{9}$ When the net trade of paper for recycling and the losses during the reprocessing were taken into account, the recycling rate in the reconciled model decreased to $58 \pm 3 \%$ and $51 \pm 3 \%$, respectively.

Static Substance Flow Analysis. The estimated amounts of BPA, DEHP, and MOHs added per year are provided in Table S7 and the derived transfer coefficients for each of the chemicals in the paper cycle processes are available from Tables S15-S21 (BPA), Tables S22-S28 (DEHP), and Tables S29-S35 (MOHs).

The majority of BPA was added in paper production through incorporation into the thermal paper matrix (Figure S2). The model-based amount of BPA added in production (i.e., 850 tonnes) was somewhat lower than the estimates made by the EU (1890 tonnes) for the years $2005-2006 .{ }^{38}$ Such a discrepancy in values might be the result of the reduced use of BPA in thermal paper through the gradual substitution with BPA alternatives such as bisphenol S. ${ }^{43}$ Thermal paper is a specialty paper that is accounted for in the OP products. Hence, the presence of BPA in the remaining six paper product categories exiting paper production was the direct result of the recycling of paper containing BPA. Certain ink and glue formulations may also include BPA as a plasticizer and plasticizer precursor, which are added to paper products in the paper conversion step. After being used, the majority of paper containing BPA ends up in the residual waste. This is a potential result of BPA contamination being recognized by the industry and consumers, and most of the thermal paper is already being diverted from the paper intended for recycling. Data from Denmark suggest that only 5\% of thermal paper receipts end up in paper for recycling, ${ }^{36}$ while the average values for the EU (ca. 30\%) are significantly higher. ${ }^{38}$

The detailed substance flow of DEHP in the paper cycle is presented in Figure S3. While the largest part of DEHP was used in the paper conversion step, a significant share of the substance was reintroduced into the cycle through paper recycling. In our model, the intentionally added DEHP (980 tonnes) was well above the 325 tonnes estimated by Lee et al. ${ }^{58}$ This difference may likely result from the fact that Lee et al. ${ }^{58}$ only accounted for DEHP used in inks. However, DEHP is also used in other applications, such as adhesives and glue preparations, accounting for 7000 tonnes annually. ${ }^{59}$ Although adhesives and glues are applied to paper and board materials, no quantitative data of the shares allocated to specific materials (paper, metal, plastic, textile, etc.) are available. Most of the DEHP reintroduced into the cycle was accumulated mainly in "case material", followed by "newsprint", and to a lower extent in the other paper products (Figure S3). "Case material" contains a considerable amount of recycled fibers, predominantly from paper grades B and C, which contained the highest amounts of DEHP.

MOHs in the paper cycle are documented in Figure S4. On the basis of the model results, 81000 tonnes of MOHs were added into the paper conversion process (Table S7). The largest flow of $\mathrm{MOH}$ in the products was in "case materials", primarily through the recycling process, which feeds mostly grade B paper (containing the most of MOHs among the discarded paper grades) into it. Once the paper was converted into paper products, NP and OG became important sources of mineral oils in the material loop. Mineral oils are mostly used as ink solvents in the printing processes, ${ }^{17}$ which explains such an increase. A significant increase of $\mathrm{MOH}$ in $\mathrm{H} \& \mathrm{~S}$ paper products was not a result of the intentional addition of $\mathrm{MOHs}$ in the paper conversion. This is because MOHs in this fraction were mainly due to potential contamination in the use phase. While considerable amounts of $\mathrm{MOHs}$ were removed from the cycle 

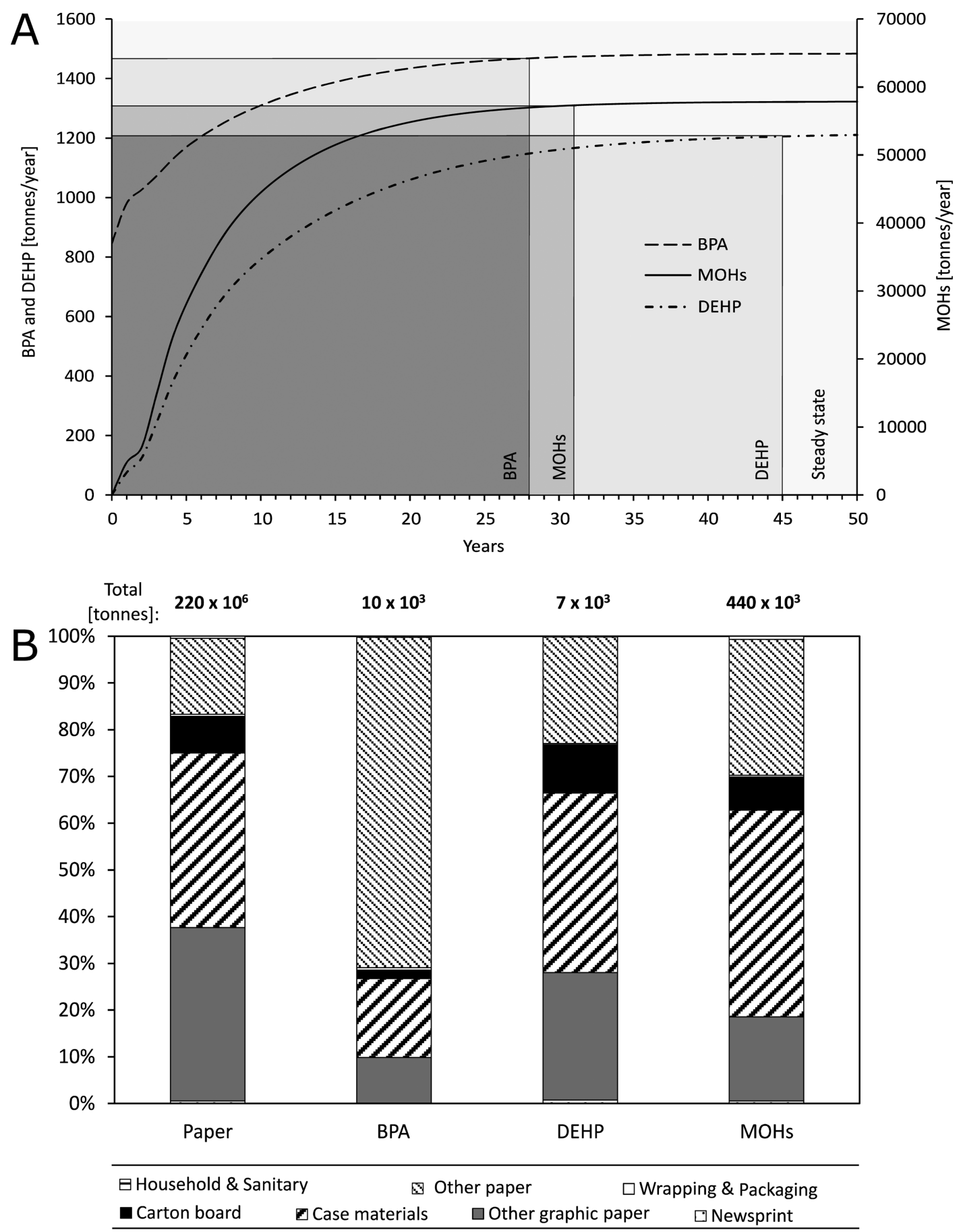

Figure 2. (A) Evolution of chemical flows in the paper products in the base case model (i.e., reference scenario, SC0). The shaded areas represent periods of accumulation for BPA, DEHP, and MOHs, as well as the (quasi) steady state achieved; (B) total in-use stock of paper, BPA, DEH, and MOHs in the various paper product groups after a steady state was reached.

through paper ending up in the residual waste, the majority of mineral oils were fed back into paper production.

Dynamic Model Outcome: Cycling of Chemicals. In the dynamic model, the amount of paper produced every year was kept constant. The paper collected for recycling was used for production, as given by the production model (Table S9), and the remainder was provided by virgin pulp. The initial system was assumed to be chemical free and the chemicals were introduced at constant rates (Table S7). Paper recycling resulted in increasing amounts of chemicals over time. As presented in Figure 2A, the period until a quasi-steady state (chemical flows in products reach $99 \%$ of the maximum) differed for the three chemicals: 28 (BPA), 45 (DEHP), and 31 years (MOHs). In all three cases the accumulation period would reduce if no minimum lifetimes were assumed (section 8 (Supporting Information)). In the steady state, the removal of chemicals from the cycle was equal to the additions per year. The accumulation of DEHP and MOHs was more gradual than that of BPA (Figure 2A). The addition of BPA in the production of paper (hence, the curve does not start at 0 ), and the fact that most of thermal paper was routed to residual waste (Table S19), 

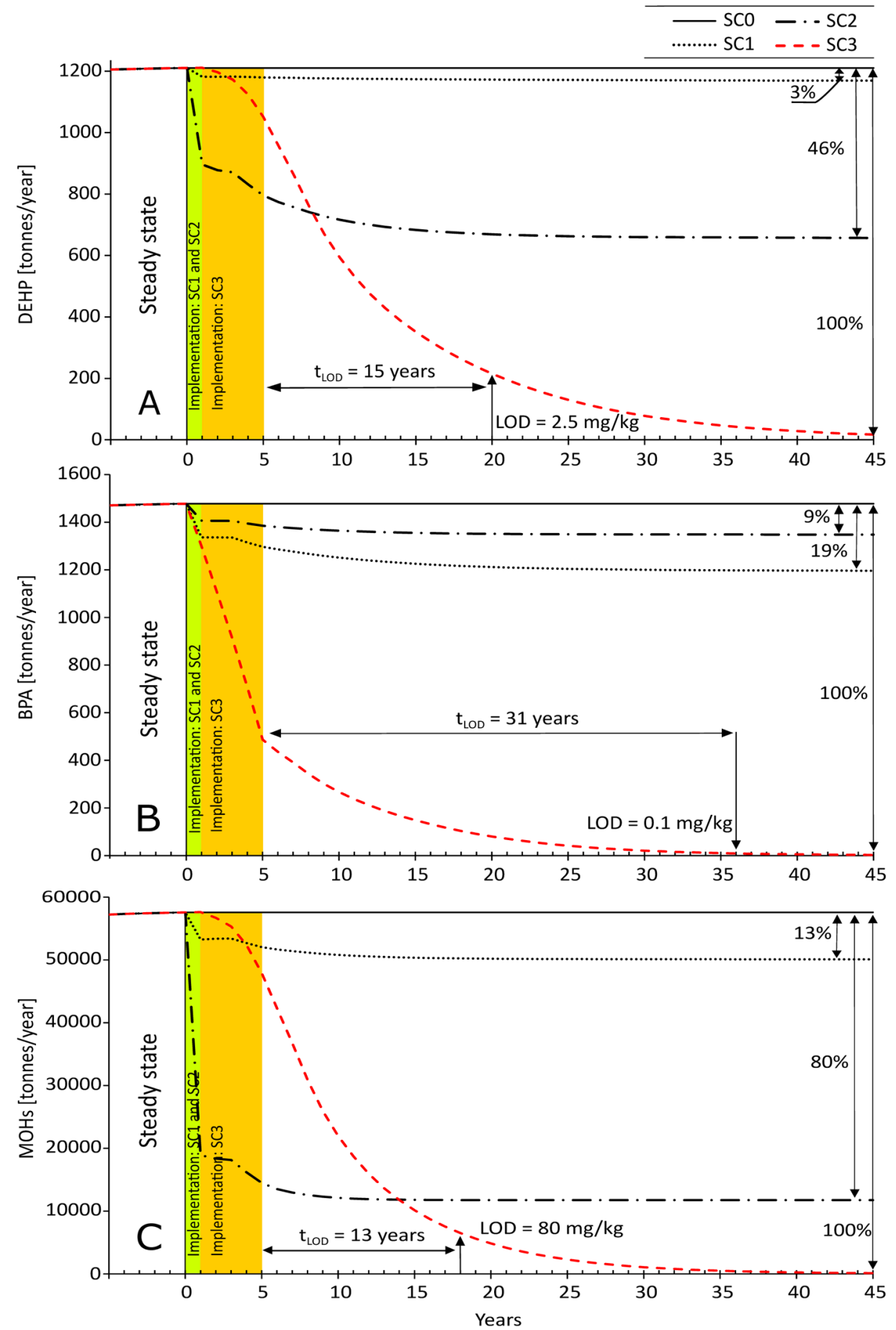

Figure 3. Evolution of BPA (A), DEHP (B), and MOHs (C) flows in the paper products (output of paper production). The shaded areas represent the implementation periods for $S C 1, S C 2$, and SC3. LOD: limit of detection; $t_{\mathrm{LOD}}$ : time required to achieve insignificant concentrations of the respective chemicals.

led to a relatively fast establishment of steady state conditions in the paper cycle.

Once the steady state was reached, the amount of paper and chemicals in the in-use stock were (practically) constant over time (Figure 2B). Most of the paper in the in-use stock was constituted by OG, CM, OP, and CB. The total paper stock was estimated to be 220 Mtonnes, which is equivalent to $470 \mathrm{~kg} /$ capita and in agreement with the estimated $410 \mathrm{~kg} /$ capita for Germany in $2010 .^{27}$ Of the three chemicals, most were found in
CM (DEHP and MOHs) or OP (BPA), followed by OG and the remaining paper products.

Scenario Analysis. The evolution of BPA, DEHP, and $\mathrm{MOHs}$ levels in paper products, as the result of the scenario implementations, is provided in Figure 3A, B, and C. The results indicated that the degree of chemical removal in paper products might vary significantly between the scenarios. In all of the scenarios (SC1-SC3), the measures indicated an initial reduction in chemical flows, followed by a leveling of the chemical contents at new, lower levels. The optimization of paper 
collection ( $\mathrm{SC} 1)$ resulted in reductions for the three chemicals assessed, ranging from 3\% (for DEHP) to 19\% (for BPA). This indicated that fractions of discarded paper containing the chemicals in focus (e.g., BPA in "other paper") were already largely diverted from the recycling loop into waste treatment alternatives (e.g., landfilling, incineration, etc.).

The detailed results of the optimized collection scenario (SC1) are presented in Table S36. Optimization for the chemicals individually may lead to somewhat contradictory conclusions, for example, in the case of BPA, CB should not be collected at all, while for MOHs the collection efficiency should be increased from the current $53 \%$ to $89 \%$. The results show that for all three chemicals, the collection efficiencies for relatively "clean" paper flows (i.e., NP and OG) should either be maintained at the current level or be increased, while other fractions ( $\mathrm{CB}, \mathrm{OP}$, and WP) had to be diverted from collection in order to reduce the presence of both BPA and DEHP. It is worth mentioning that $100 \%$ collection efficiency of any fraction is purely indicative and would not be feasible in practice. The chemical flows in some paper product groups increased due to increased collection efficiencies (negative values in Table S36). However, overall, the optimized collection resulted in the reduction of BPA, DEHP, and MOHs in the paper products by $19 \%, 3 \%$, and $13 \%$, respectively. The rather limited potential for reduction was also related to the constraint of maintaining the current recycling rate. For instance, allowing the recycling rate to decrease by $5 \%$ would enable the reduction of the flows of BPA, DEHP, and MOHs by $25 \%, 26 \%$, and $27 \%$, respectively (Table S37). This however is against the general trends in paper production in which recycling rates have been constantly increasing. ${ }^{29}$

The effects of increasing the removal efficiency (SC2) were the lowest for BPA (9\%), followed by DEHP (46\%), and MOHs (80\%). The relatively small reduction observed for BPA was the result of (i) limited improvements in the removal efficiency (from $10 \%$ to $20 \%$ ) and (ii) direct use of BPA in paper production. The results indicated that, in order to achieve a substantial reduction in the presence of chemicals in paper products, major improvements in the processes designed for contaminant removal should be made. As specified in the scenario definition (Table S3), increased removal efficiency was potentially associated with a slight reduction in paper yield, potentially resulting in a trade-off between the chemical flows (quality) and paper yields (quantity) from recycling.

As expected, phasing out the chemicals was the most effective way to reduce their flows in the paper products. However, this still requires a considerable period after the end of the phase out period itself before the chemical content of paper can be considered insignificant (below the LOD). As evident from Figure 3, this period was 15 years for DEHP, 13 years for MOHs, and 31 years for BPA. Additionally, in the model, all of the chemicals were assumed to be intentionally added to the paper material. Therefore, chemical contamination during use, waste management, or chemicals in imports to conversion or use might limit the effect of phasing out a chemical. Consequently, actual phase-out may be less effective and potentially result in longer phase-out periods than estimated here.

Implications for Material Recycling. The results of the scenario analysis highlight important aspects that need to be considered in relation to recycling of waste materials into high quality products. The trade-off between the quality and quantity of recycled materials was clearly illustrated through scenario one (SC1): substantial reductions of chemical flows could not be achieved through improved source-segregation of paper waste without lowering the mass-based recycling rates. For instance, lowering the recycling rate by $5 \%$ would enable the optimized paper collection to support higher removal of chemicals (particularly for DEHP and MOHs), compared to the base case. Similarly, scenario two (SC2) indicated that substantial contaminant removal in the recycling (and reprocessing) process could be achieved only through major technological improvements, which may lead to potential increases in residue generation.

In the present case, the substantial differences between the scenarios and comparative nature of the scenario analysis allowed for indirect sensitivity analysis of important modeling parameters while providing robust conclusions merely sensitive to the assumptions taken. However, changes of the paper product lifetime functions in the dynamic model have influence on the rate of mitigation measures effect and on the estimated in-use stocks of paper and chemicals (see section 8 of the Supporting Information for an analysis of the effect of alternative minimum lifetime assumption on the model results). Therefore, validated, empirically based paper product-specific lifetime functions would be a valuable asset for further investigating the dynamics of the paper cycle. Furthermore, the assumption of chemical concentrations in imported paper products being equal to domestically produced ones is a simplification, which might overestimate the effectiveness of mitigation measures implemented within Europe, in particular concerning the phase out of specific chemicals. In addition, rejecting the assumption of constant paper consumption was not explicitly assessed, but is expected to only marginally speed up the effects of mitigation strategies by increasing the amounts of virgin fiber in the paper cycle.

Because of the general importance of clean material cycles and the challenge of directing problematic substances to appropriate sinks, ${ }^{60,61}$ the presented modeling approach could be applied also to other product cycles and chemicals. As such, the approach may potentially support detailed analysis of material recycling in general as well as incorporate new data as they become available. While investigating potential human exposure to chemicals contained in consumer products was beyond the scope of this study, including exposure modeling could be a potential future step in assessing the impacts of chemical contamination in material cycles. While detailed and consistent data representing material compositions and chemical fates within the material cycle are scarce, and improvements are certainly encouraged, the modeling included in this study clearly demonstrates that material recycling should be a conscious balance between high quality (secondary) products and high (mass based) recycling rates. Finally, the work was not aiming to provide detailed discussion on policy implications. However, material recycling policies should not only reflect the mass of materials collected for recycling, but also, to improve the quality of the secondary products, combine recycling initiatives with technological development and strategies for contaminant removal from the material cycles.

\section{ASSOCIATED CONTENT}

\section{Supporting Information}

The Supporting Information is available free of charge on the ACS Publications website at DOI: 10.1021/acs.est.6b01791.

Eight sections containing relevant tables (Table S1-S37) and figures (Figures S1-S5)(PDF) 


\section{AUTHOR INFORMATION}

\section{Corresponding Author}

*Phone: (+45) 45251602; e-mail: kosp@env.dtu.dk; address: Bygningstorvet, Building 115, 2800 Kgs. Lyngby, Denmark.

\section{Notes}

The authors declare no competing financial interest.

\section{ACKNOWLEDGMENTS}

We thank Lisbet Brusendorff for her work on the abstract graphics. Danish Research Council is acknowledged for its financial support through the 3R Research School and the IRMAR project (Grant No. 11-116775).

\section{REFERENCES}

(1) Brundtland, G.; Khalid, M.; Agnelli, S.; Al-Athel, S.; Chidzero, B.; Fadika, L.; Hauff, V.; Lang, I.; Shijun, M.; Morino de Botero, M.; et al. Our Common Future ('Brundtland report'): Report for the World Commission on Environment and Development; United Nations: New York City, USA, 1987.

(2) WRAP. Environmental Benefits of Recycling An International Review of Life Cycle Comparisons for Key Materials in the UK Recycling Sector; Waste \& Resource Action Programme (WRAP): Banbury, UK, 2006.

(3) US EPA. Advancing Sustainable Materials Management: Facts and Figures 2013. Assessing Trends in Material Generation, Recycling and Disposal in the United States. U.S. Environmental Protection Agency (EPA): Washington, DC, USA, 2015.

(4) Pivnenko, K.; Astrup, T. F. The challenge of chemicals in material lifecycles. Waste Manag. 2016, 56, 1-2.

(5) CEPI. CEPI Sustainability Report 2013. European Paper IndustryAdvancing the Bioeconomy; Confederation of European Paper Industries (CEPI): Brussels, Belgium, 2013.

(6) Pivnenko, K.; Eriksson, E.; Astrup, T. F. Waste paper for recycling: Overview and identification of potentially critical substances. Waste Manage. 2015, 45, 134-142.

(7) Muncke, J. Exposure to endocrine disrupting compounds via the food chain: Is packaging a relevant source? Sci. Total Environ. 2009, 407 (16), 4549-4559.

(8) BIR. BIR Global Facts \& Figures. Recovered Paper Market in 2012; Bureau of International Recycling (BIR): Brussels, Belgium, 2012.

(9) Keränen, J. T.; Ervasti, I. Amounts of non-fibrous components in recovered paper. Resour. Conserv. Recycl. 2014, 92, 151-157.

(10) Ervasti, I.; Miranda, R.; Kauranen, I. Paper recycling framework, the "Wheel of Fiber. J. Environ. Manage. 2016, 174, 35-44.

(11) Ali, M.; Sreekrishnan, T. Aquatic toxicity from pulp and paper mill effluents: a review. Adv. Environ. Res. 2001, 5 (2), 175-196.

(12) Zheng, M.-H.; Bao, Z.-C.; Zhang, B.; Xu, X.-B. Polychlorinated dibenzo-p-dioxins and dibenzofurans in paper making from a pulp mill in China. Chemosphere 2001, 44 (6), 1335-1337.

(13) Rana, T.; Gupta, S.; Kumar, D.; Sharma, S.; Rana, M.; Rathore, V. S.; Pereira, B. M. Toxic effects of pulp and paper-mill effluents on male reproductive organs and some systemic parameters in rats. Environ. Toxicol. Pharmacol. 2004, 18 (1), 1-7.

(14) Lacorte, S. Organic compounds in paper-mill process waters and effluents. TrAC, Trends Anal. Chem. 2003, 22 (10), 725-737.

(15) BMELV. Ausmaß der Migration unerwünschter Stoffe aus Verpackungsmaterialien aus Altpapier in Lebensmitteln (Extent of migration of undesirable substances from packaging materials made of waste paper in food); BMELV (German Federal Ministry of Food, Agriculture and Consumer Protection): Bonn, Germany, 2012; http:// download.ble.de/09HS012.pdf.

(16) Binderup, M. L.; Pedersen, G. A.; Vinggaard, A. M.; Rasmussen, E. S.; Rosenquist, H.; Cederberg, T. Toxicity testing and chemical analyses of recycled fibre-based paper for food contact. Food Addit. Contam. 2002, 19, 13-28.

(17) Biedermann, M.; Grob, K. Is recycled newspaper suitable for food contact materials? Technical grade mineral oils from printing inks. Eur. Food Res. Technol. 2010, 230 (5), 785-796.
(18) Poças, M. F.; Oliveira, J. C.; Pereira, J. R.; Hogg, T. Consumer exposure to phthalates from paper packaging: an integrated approach. Food Addit. Contam., Part A 2010, 27 (10), 1451-1459.

(19) Brunner, P. H.; Rechberger, H. Introduction. In Practical Handbook of Material Flow Analysis; CRC Press: Boca Raton, FL, USA, 2004.

(20) Chen, W.-Q.; Graedel, T. E. Anthropogenic cycles of the elements: a critical review. Environ. Sci. Technol. 2012, 46 (16), 85748586.

(21) Brunner, P. H.; Ma, H. W. Substance flow analysis an indispensable tool for goal-oriented waste management. J. Ind. Ecol. 2009, 13 (1), 11-14.

(22) Müller, E.; Hilty, L. M.; Widmer, R.; Schluep, M.; Faulstich, M. Modeling metal stocks and flows: a review of dynamic material flow analysis methods. Environ. Sci. Technol. 2014, 48 (4), 2102-2113.

(23) Laner, D.; Rechberger, H.; Astrup, T. Applying Fuzzy and Probabilistic Uncertainty Concepts to the Material Flow Analysis of Palladium in Austria. J. Ind. Ecol. 2015, 19 (6), 1055-1069.

(24) Laner, D.; Rechberger, H.; Astrup, T. Systematic Evaluation of Uncertainty in Material Flow Analysis. J. Ind. Ecol. 2014, 18 (6), 859870.

(25) Klinglmair, M.; Zoboli, O.; Laner, D.; Rechberger, H.; Astrup, T. F.; Scheutz, C. The effect of data structure and model choices on MFA results: A comparison of phosphorus balances for Denmark and Austria. Resour. Conserv. Recycl. 2016, 109, 166-175.

(26) Pivnenko, K.; Eriksson, E.; Astrup, T. F. Presence of potentially critical substances in waste paper. In Cossu, R., He, P., Kjeldsen, P., Matsufuji, Y., Reinhart, D., Stegmann, R., Eds.; Proceedings of the Fourteenth Waste Management and Landfill Symposium, S. Margherita di Pula, Sardina, Sept 30-Oct 4, 2013.

(27) Cote, M.; Poganietz, W.-R.; Schebek, L. Anthropogenic Carbon Stock Dynamics of Pulp and Paper Products in Germany. J. Ind. Ecol. 2015, 19 (3), 366-379.

(28) CEPI. Key Statistics. European Pulp and Paper Industry 2012; Confederation of European Paper Industries (CEPI): Brussels, Belgium, 2013.

(29) CEPI. Key Statistics. European Pulp and Paper Industry 2014; Confederation of European Paper Industries (CEPI): Brussels, Belgium. 2014.

(30) van der Voet, E. Substance flow analysis methodology. In $A$ Handbook of Industrial Ecology; Ayres, R. U., Ayres, L. W., Eds.; Edward Elgar Publishing Ltd: Cheltenham, UK, 2002.

(31) Jamnicki, S. Deinking possibilities in the reduction of mineral oil hydrocarbons from recovered paper grades. Cellul. Chem. Technol. 2015, 49, 677-684.

(32) Krauskopf, L. G. How about alternatives to phthalate plasticizers? J. Vinyl Addit. Technol. 2003, 9 (4), 159-171.

(33) Roy, A. S.; Bhattacharjee, M.; Mondal, R.; Ghosh, S. Development of mineral oil free offset printing ink using vegetable oil esters. J. Oleo Sci. 2007, 56 (12), 623-628.

(34) US EPA. Bisphenol A Alternatives in Thermal Paper; United States EPA: Washington, DC, 2014.

(35) Zurfluh, M.; Grob, K.; Fink, M.; Amrein, T. M. Printing newspaper free of mineral oil: report on a test run. J. Verbraucherschutz Lebensmittelsicherh. 2013, 8 (1-2), 17-25.

(36) Pivnenko, K.; Olsson, M.; Götze, R.; Eriksson, E.; Astrup, T. F. Quantification of chemical contaminants in the paper and board fractions of municipal solid waste. Waste Manage. 2016, 51, 43-54.

(37) Sevigné-Itoiz, E.; Gasol, C. M.; Rieradevall, J.; Gabarrell, X. Methodology of supporting decision-making of waste management with material flow analysis (MFA) and consequential life cycle assessment (CLCA): case study of waste paper recycling. J. Cleaner Prod. 2015, 105, $253-262$.

(38) JRC-IHCP. European Union Risk Assessment Report: 4,4'isopropylidenediphenol (Bisphenol-A); Joint Research Center, Institute for Health and Consumer Protection: Ispra, Italy, 2008.

(39) ITC. International trade in goods-Imports 2001-2013; International Trade Center (ITC): Geneva, Switzerland, 2013; http://www. intracen.org/itc/market-info-tools/statistics-import-product-country. 
(40) Edjabou, M. E.; Jensen, M. B.; Götze, R.; Pivnenko, K.; Petersen, C.; Scheutz, C.; Astrup, T. F. Municipal Solid Waste Composition: Sampling methodology, statistical analyses, and evaluation of case study. Waste Manage. 2015, 36, 12-23.

(41) BC Wood Products: Trend analysis in export markets, 2008 annual report; Pöyry: Vantaa, Finland, 2009; Vol. 3: Pulp and paper.

(42) Holik, H., Ed. Handbook of Paper and Board, 2nd revised and enlarged ed.; Wiley-VCH Verlag GmbH \& Co. KGaA: Weinheim, Germany, 2013.

(43) Pivnenko, K.; Pedersen, G. A.; Eriksson, E.; Astrup, T. F. Bisphenol A and its structural analogues in household waste paper. Waste Manage. 2015, 44, 39-47.

(44) Liao, C.; Kannan, K. High levels of bisphenol A in paper currencies from several countries, and implications for dermal exposure. Environ. Sci. Technol. 2011, 45 (16), 6761-6768.

(45) Liao, C.; Kannan, K. Widespread occurrence of bisphenol A in paper and paper products: implications for human exposure. Environ. Sci. Technol. 2011, 45 (21), 9372-9379.

(46) Biedermann, M.; Ingenhoff, J.-E.; Zurfluh, M.; Richter, L.; Simat, T.; Harling, A.; Altkofer, W.; Helling, R.; Grob, K. Migration of mineral oil, photoinitiators and plasticisers from recycled paperboard into dry foods: a study under controlled conditions. Food Addit. Contam., Part A 2013, $30(5), 885-898$.

(47) Droz, C.; Grob, K. Determination of food contamination by mineral oil material from printed cardboard using on-line coupled LCGC-FID. Zeitschrift für Leb. und -forsch. A 1997, 205 (3), 239-241.

(48) Biedermann, M.; Uematsu, Y.; Grob, K. Mineral oil contents in paper and board recycled to paperboard for food packaging. Packag. Technol. Sci. 2011, 24 (2), 61-73.

(49) Lorenzini, R.; Fiselier, K.; Biedermann, M.; Barbanera, M.; Braschi, I.; Grob, K. Saturated and aromatic mineral oil hydrocarbons from paperboard food packaging: estimation of long-term migration from contents in the paperboard and data on boxes from the market. Food Addit. Contam., Part A 2010, 27 (12), 1765-1774.

(50) Jamnicki, S.; Lozo, B.; Rutar, V.; Barušić, L. A study on the food contact suitablity of recycled paper and board. Papiripar 2012, No. 1935, $14-20$.

(51) Hanecker, E.; Ewald, C.; Kersten, A. Mineralölentfernung aus Altpapierstoffen. In Workshop "Mineralöl in Lebensmitteln: München, Germany, 2012.

(52) Ewald, C.; Kersten, A.; Putz, H.-J. Mineralölentfrachtung von Altpapierstoffen durch thermisch-mechanische Maßnahmen (Mineral oil extraction of waste paper materials by thermal-mechanical action). Papierfabrikation und Mechanische Verfahrenstechnik, Technische Universität Darmstadt: Darmstadt, Germany, 2013; http://www.pmv. tu-darmstadt.de/media/fachgebiet_pmv/bibliothek_1/aif veroeffentlichungen/AiF 17272 Mineraloelentfrachtung Schlussbericht final 14-07-09 mit unterschr Titelblatt.pdf.

(53) ERPC. European Declaration on Paper Recycling; European Recovered Paper Council (ERPC): Brussels, Belgium, 2011.

(54) Ervasti, I.; Miranda, R.; Kauranen, I. A global, comprehensive review of literature related to paper recycling: A pressing need for a uniform system of terms and definitions. Waste Manage. 2016, 48, 6471.

(55) Bailey, R.; Bras, B.; Allen, J. K. Measuring material cycling in industrial systems. Resour. Conserv. Recycl. 2008, 52 (4), 643-652.

(56) Chen, W.-Q. Recycling Rates of Aluminum in the United States. J. Ind. Ecol. 2013, 17 (6), 926-938.

(57) Hashimoto, S.; Moriguchi, Y. Proposal of six indicators of material cycles for describing society's metabolism: from the viewpoint of material flow analysis. Resour. Conserv. Recycl. 2004, 40 (3), 185-200.

(58) Lee, J.; Pedersen, A. B.; Thomsen, M. The influence of resource strategies on childhood phthalate exposure-The role of REACH in a zero waste society. Environ. Int. 2014, 73, 312-322.

(59) Data on manufacture, import, export, uses and releases of bis(2ethylhexyl)phthalate (DEHP) as well as information on potential alternatives to its use; COWI: Kgs. Lyngby, Denmark, 2009.

(60) Brunner, P. H. Clean cycles and safe final sinks. Waste Manage. Res. 2010, 28 (7), 575-576.
(61) Kral, U.; Kellner, K.; Brunner, P. H. Sustainable resource use requires "clean cycles" and safe "final sinks. Sci. Total Environ. 2013, $461-462,819-822$.

\section{NOTE ADDED AFTER ASAP PUBLICATION}

This article originally published with an incorrect version of Figure 3. The correct version published on September 20, 2016. 